\title{
Impactos ambientais do manejo agroecológico da caatinga no Rio Grande do Norte
}

\author{
Hilton Felipe Marinho Barreto(1), João Paulo Guimarães Soares (2), Débora Andréa Evangelista Façanha Morais ${ }^{(3)}$, \\ Andréa Cristina Capriatta Silva( ${ }^{(3)}$ e Ana Karina Dias Salman ${ }^{(4)}$
}

\begin{abstract}
(1)Instituto Federal de Educação, Ciência e Tecnologia do Rio Grande do Norte, Campus Apodi, Sítio Lagoa do Clementino, no 999, BR 233, Zona Rural, CEP 59700-971 Apodi, RN. E-mail: felipe.barreto@ifrn.edu.br (2)Embrapa Cerrados, BR 020, Km 18, Caixa Postal 08223, CEP 73310-970 Planaltina, DF. E-mail: jp.soares@cpac.embrapa.br ${ }^{(3)}$ Universidade Federal Rural do Semiárido, BR 110, Km 47, Bairro Pres. Costa e Silva, CEP 59625-900 Mossoró RN. E-mail: debora_ufersa@hotmail.com, deiavet@hotmail.com (4)Embrapa Rondônia, BR 364, Km 5,5, CEP 76815-820 Porto Velho, RO. E-mail: aksalman@cpafro.embrapa.br.
\end{abstract}

Resumo - O objetivo deste trabalho foi avaliar os impactos ambientais do manejo agroecológico da caatinga, em unidades de produção familiar no Rio Grande do Norte, pelo método Ambitec de produção animal dimensão ambiental, desenvolvido pela Embrapa Meio Ambiente. Foram avaliadas sete unidades de produção familiar, em quatro projetos de assentamentos de reforma agrária do Município de Apodi, RN. Os dados para o levantamento foram obtidos por meio de questionários aplicados aos representantes das unidades produtivas familiares, que atribuíram, a cada variável estudada, um valor que representou a alteração proporcionada pela implementação da tecnologia. Após a inserção dos coeficientes de alteração de cada variável dos indicadores por unidade de produção, o coeficiente de impacto foi automaticamente calculado por meio da planilha Ambitec. O manejo agroecológico da caatinga resultou num impacto ambiental positivo, e suas maiores contribuições foram relacionadas aos efeitos positivos dos seguintes indicadores: capacidade produtiva do solo, uso de insumos materiais, qualidade do produto e diminuição da emissão de poluentes à atmosfera. Dois indicadores geraram efeitos negativos: o uso de energia e o uso de recursos naturais. Pela superioridade dos benefícios gerados, o manejo agroecológico da caatinga é uma inovação tecnológica geradora de impactos ambientais positivos.

Termos para indexação: agricultura familiar, agroecologia, degradação ambiental, meio ambiente, sustentabilidade.

\section{Environmental impacts of caatinga agroecological handling in Rio Grande do Norte, Brazil}

\begin{abstract}
The objective of this work was to evaluate the environmental impacts of caatinga agroecological handling, in production unities of family farms, in Rio Grande do Norte, using the method Ambitec of animal production - environmental dimension, developed by Embrapa Meio Ambiente. Seven family farm production units were evaluated within four projects of agrarian reform in the county of Apodi, RN, Brazil. The data for surveying were obtained through applying queries to the responsibles for the production units, who attributed - to each studied variable - a value which represented the alteration resulted from the technology implementation. After insertion of the alteration coeficients of each indicator by production unit, the impact coeficients was automatically calculated using Ambitec sheet. The caatinga agroecological handling had a positive environmental impact, and its major contributions were related to the positive effects of the following indicators: soil production capacity, use of material input, product quality, and decrease of pollution emission to atmosphere. Two indicators had negative impact scores: energy use and use of natural resources. By the superiority of the benefits, caatinga agroecological handling is a technology innovation which generates positive environmental impacts.
\end{abstract}

Index Terms: family agriculture, agroecology, environmental degradation, environment, sustainability.

\section{Introdução}

A pastagem nativa é o principal alimento dos rebanhos do semiárido e é explorada em sua maior parte por sistemas extensivos (Holanda Júnior, 2006).
Atualmente, a Caatinga produz apenas $4.000 \mathrm{~kg} \mathrm{ha}^{-1} \mathrm{de}$ matéria seca por ano, dos quais somente $400 \mathrm{~kg} \mathrm{ha}^{-1}$ estão na forma de pastagem disponível (Araújo Filho et al., 1999). Além da baixa capacidade de suporte da Caatinga, tem-se a redução das áreas disponíveis

Pesq. agropec. bras., Brasília, v.45, n.10, p.1073-1081, out. 2010 
dos estabelecimentos pecuários, pois, segundo o Departamento Intersindical de Estatística e Estudos Socioeconômicos (2008), 73,7\% das propriedades rurais apresentam área igual ou inferior a 50 ha e, desses estabelecimentos, 42,8\% apresentam área igual ou inferior a 10 ha.

Uma das pressões impostas à Caatinga, na busca pelo aumento da disponibilidade de alimentos para os animais, é o cultivo de pastagens. Quanto ao cultivo, de acordo com Sampaio et al. (2005), os prejuízos ambientais se iniciam com o desmatamento e a substituição da vegetação nativa por outra cultivada e de porte e ciclo de vida diferentes. Atrelada à substituição da vegetação está a retirada dos produtos agrícolas que, sem a devida reposição dos nutrientes, leva à perda da fertilidade e da capacidade produtiva do solo; e o uso indiscriminado de agrotóxicos que tem trazido sérios danos ao meio ambiente e, muitas vezes, perigo aos aplicadores de agrotóxicos, aos consumidores e aos animais (Lima, 2003). Além disso, têm-se a contaminação e a degradação dos recursos hídricos, ocasionadas pela lixiviação dos adubos químicos utilizados e a salinização dos solos, ocasionada pelo uso de água com teores elevados de sais, pelo mau manejo dos ciclos de fornecimento de água e pela ausência de drenagem nas pastagens irrigadas (Sampaio et al., 2005).

Como alternativa às pressões exercidas à Caatinga, tem-se o seu manejo agroecológico, o qual envolve a formação dos sistemas agroflorestais que, de acordo com Costa et al. (2002), classificam-se em silviagrícolas, silvipastoris e agrissilvipastoris. Esses sistemas, segundo Melo et al. (2002), valorizam a biodiversidade, garantem a estabilidade e elevam a produtividade da terra, aumentam a oferta de alimentos e permitem uma alimentação equilibrada mesmo nos anos de deficit pluvial. Segundo Araújo Filho et al. (2006), essa técnica também diversifica a produção, melhora a fertilidade do solo, aumenta a oferta de forragem, reduz a degradação ambiental pela exclusão de queimadas e do desmatamento, fixa a agricultura itinerante, e melhora a renda e a qualidade de vida dos agricultores.

Diferentes trabalhos têm sido desenvolvidos com o uso do manejo agroecológico da Caatinga (Araújo Filho, 1992; Cavalcante et al., 2005, 2007), entretanto, estes trabalhos não mensuraram de forma quantitativa o conjunto dos impactos ambientais, cuja avaliação é possível com uso do Sistema Ambitec. Resultados da literatura mostram apenas os coeficientes técnicos obtidos, como valores de produção animal por área, incremento da diversidade vegetal, preservação do bioma etc., o que reduz consequentemente o impacto ambiental (Araújo Filho et al., 2006), porém, sem avaliar quantitativamente esse impacto.

Pela metodologia Ambitec, que fornece uma plataforma socioambiental para avaliação de impactos, pode-se auferir, com acuidade, quais fatores aumentam ou diminuem o impacto ambiental por meio da mensuração de índices numéricos padronizados, comparáveis em diferentes condições e em diferentes regiões, biomas e com uso de diferentes tecnologias (Rodrigues et al., 2003).

O Sistema Ambitec (Rodrigues \& Campanhola, 2003) vem sendo utilizado anualmente, no contexto institucional de pesquisa e desenvolvimento na Embrapa, para a avaliação de impactos ambientais das inovações tecnológicas oferecidas. O Sistema Ambitec foi desenvolvido especialmente para atender a uma demanda institucional: a de avaliar impactos ambientais de inovação tecnológica agropecuária, segundo objetivos de desenvolvimento sustentável, por meio de uma plataforma prática de execução simples, de baixo custo, e passível de aplicação a todo universo tecnológico e ambiental de inserção institucional (Rodrigues et al., 2003). Durante este período, o método vem passando por constante construção e aperfeiçoamento, entretanto foi validado durante o período 2001-2008 pelo balanço social da Embrapa (Balanço social da pesquisa agropecuária brasileira, 2006, 2009) e por Rodrigues et al. (2006).

O Ambitec aborda os impactos da tecnologia segundo os seguintes aspectos ambientais: o alcance; a eficiência - uma medida do resultado esperado da tecnologia em relação à conservação de insumos e aos efeitos ambientais; o potencial para promover a recuperação da qualidade ambiental; a conservação - relativa ao efeito da tecnologia sobre os compartimentos dos ecossistemas; qaualidade do produto ; o capital social; e o bem-estar e saúde do animal. O impacto ambiental é avaliado segundo o efeito esperado da tecnologia sobre esses aspectos e indicadores, em uma planilha eletrônica que expressa os resultados em forma gráfica. No caso do segmento específico da produção animal, utilizado no presente trabalho, aborda o alcance, a eficiência, a conservação ambiental, a recuperação ambiental, 
a qualidade do produto e bem-estar e saúde animal, constituídos dos indicadores e seus componentes.

Os componentes dos indicadores são valorados com coeficientes de alteração, conforme conhecimento pessoal do adotante/responsável pelo estabelecimento. Os entrevistados respondem a perguntas sobre as diferentes questões relacionadas à produção, à preservação dos recursos naturais e às suas condições de vida na unidade de produção, em dois momentos, ou seja antes e depois da adoção do manejo agroecológico da caatinga.

Grande parte das alterações constitui-se de conhecimento tácito do proprietário ou responsável e é obtida diretamente com o auxílio do questionário. Outros indicadores requerem a avaliação sensorial do responsável. Algumas variáveis como a qualidade da água devem ser analisadas no local por meio de kit diagnóstico. Outras variáveis de qualidade de solo e água são analisadas em laboratório (Rodrigues \& Campanhola, 2003).

Como é um método de abrangência, sua utilização, deve promover seu aperfeiçoamento contínuo, para aumentar sua contribuição ao tema.

No presente trabalho foi priorizada somente a avaliação do impacto ambiental pelo uso da tecnologia de manejo agroecológico da Caatinga, que se ajustou perfeitamente às atividades desenvolvidas na região, em razão do caráter de recuperação ambiental já descrito. O principal avanço do uso da metodologia Ambitec é a possibilidade de avaliação do manejo agroecológico dessa Região que, até então não, havia sido mensurada nesses padrões, o que possibilita o redirecionamento de algumas práticas utilizadas, e a retirada e inclusão de outras que contribuirão para o melhor manejo do bioma, com o mínimo de impacto.

O presente trabalho teve como objetivo avaliar os impactos ambientais do manejo agroecológico da Caatinga, em unidades de produção familiar no Rio Grande do Norte, por meio do método Ambitec -produção animal.

\section{Material e Métodos}

O levantamento foi realizado no Município de Apodi, localizado na mesorregião Oeste Potiguar, microrregião da Chapada do Apodi (Brasil, 2005), no Estado do Rio Grande do Norte, a $5^{\circ} 39^{\prime} 50^{\prime \prime} \mathrm{S}$ e $37^{\circ} 47^{\prime} 56^{\prime \prime} \mathrm{W}$, a cerca de $334 \mathrm{~km}$ da Capital, em uma área de $1.549 \mathrm{~km}^{2}$
(Brasil, 2005). Sua classificação climática, conforme Köppen, é do tipo Bswh, clima quente e semiárido, com temperatura média anual de $28,1^{\circ} \mathrm{C}$, umidade relativa média anual de $68 \%$ e 2.700 horas de insolação (Governo do Rio Grande do Norte, 2010). O município apresenta precipitação pluvial anual média em torno de $833,5 \mathrm{~mm}$ e período chuvoso concentrado nos meses de março a maio (Governo do Rio Grande do Norte, 2005).

Os dados para o levantamento foram obtidos a partir das planilhas do Ambitec - produção animal (Rodrigues et al., 2003), e as entrevistas foram realizadas entre os anos de 2009 e 2010, aos representantes de sete unidades produtivas familiares, onde cada produtor constituiu uma unidade amostral de impacto ambiental da tecnologia.

Esses agricultores, que anteriormente desenvolviam práticas exclusivamente extrativistas, passaram a adotar, há pelo menos dois anos, o manejo agroecológico da Caatinga, que consistiu de rebaixamento, raleamento e enriquecimento, conforme Araújo Filho et al. (2006), associados aos princípios agroecológicos.

Os princípios agroecológicos utilizados compõemum conjunto de práticas conservacionistas, que propiciaram o reflorestamento, a extinção das queimadas, o uso racional de máquinas agrícolas, da energia e dos insumos materiais, assim como a eliminação do uso de produtos químicos como, agrotóxicos, adubos químicos, medicamentos alopáticos etc.. Todos esses procedimentos são descritos pela instrução normativa (IN 64) para sistemas orgânicos de produção animal e vegetal no Brasil (Brasil, 2009), que englobam todas as atividades agroecológicas e biodinâmicas, antes desenvolvidas separadamente. Os agricultores recebem acompanhamento periódico, por meio do Projeto Manejo da Caatinga no Sertão do Apodi, da Cooperativa Terra Livre, em convênio com o Projeto Dom Helder Câmara.

Os agricultores 1 e 2 são moradores do Projeto de Assentamento e Reforma Agrária (P. A.) Lage do Meio, distante $29 \mathrm{~km}$ da sede do Município de Apodi. O agricultor 1 realizou, em uma área de 2 ha, o raleamento, o rebaixamento e o enriquecimento da Caatinga, com introdução do feijão-guandu (Cajanus cajan), da leucena (Leucaena leucocephala) e da moringa (Moringa oleifera), em 2004. O agricultor 2 iniciou a manipulação da Caatinga em 2006, enriquecendo-a com a cunhã (Clitoria ternatea) e 
reflorestando-a com essências nativas ou adaptadas ao semiárido.

No P. A. Moacir Lucena, situado a $23 \mathrm{~km}$ de Apodi, $\mathrm{RN}$, residem os agricultores 3 e 4 . O agricultor 3 realiza, desde 2002, o raleamento em faixas, o rebaixamento, o enriquecimento e o reflorestamento com fruteiras adaptadas, numa área de 2 ha. $\mathrm{O}$ quarto agricultor iniciou a manipulação da Caatinga em 2003, e realizou o enriquecimento com a leucena e a moringa, e o reflorestamento pela implantação de essências nativas, numa parcela de 1,5 ha.

$\mathrm{O}$ agricultor 5 reside no P. A. Nova Descoberta, situado a $15 \mathrm{~km}$ da sede do Município de Apodi, realizou em 2007, numa parcela de 2 ha, o raleamento do mufumbo (Combretum leprosum). No P. A. Tabuleiro Grande, reside o agricultor 6 que manejou agroecologicamente 2 ha de Caatinga e utilizou o raleamento, o rebaixamento, o enriquecimento $\mathrm{e}$ a introdução de fruteiras adaptadas às condições climáticas da região. $\mathrm{O}$ agricultor 7 está domiciliado no Sítio Carpina, a cerca de $6 \mathrm{~km}$ da sede do Município, explora 4,2 ha, dos quais 0,33 ha foi enriquecido com leucena.

O sistema de avaliação de impactos ambientais utilizado foi o Ambitec-produção animal, desenvolvido pela Embrapa Meio Ambiente e composto por um conjunto de planilhas eletrônicas (MS-Excel) que representam os seguintes aspectos ambientais estudados: eficiência tecnológica, conservação ambiental, recuperação ambiental e qualidade do produto (Irias et al., 2004). Também compõe o sistema a planilha referente à avaliação de impacto ambiental da tecnologia, que compila os dados inseridos nos aspectos mencionados anteriormente (Ávila et al., 2008).

Os aspectos ambientais são formados por matrizes de ponderação automatizadas, que representam os indicadores compostos por variáveis. No sistema, os aspectos apresentam em seu conjunto os seguintes indicadores: uso de insumos materiais (veterinários), uso de energia, uso de recursos naturais, atmosfera, capacidade produtiva do solo, qualidade da água, biodiversidade, recuperação ambiental e qualidade do produto (Rodrigues et al., 2003). As variáveis são mensuradas com base no coeficiente de alteração, ou seja, pela atribuição, a cada variável estudada, de um valor que representa a alteração proporcionada pela implementação da tecnologia, em que o coeficiente +3 indica uma grande influência positiva no componente;
+1 , moderada influência positiva no componente; 0 , componente inalterado; -1 , moderada influência negativa no componente e -3 , grande influência negativa no componente (Rodrigues et al., 2003; Tupy \& Primavesi, 2006).

Nas entrevistas com os agricultores, foi utilizada a própria planilha do Ambitec - produção animal, impressa e levada ao campo, na qual, conforme o questionamento feito a cada agricultor avaliado, foram atribuídos os valores de $-3 \mathrm{a}+3$, inseridos na respectiva variável de cada indicador. Após a coleta de dados no campo, as planilhas impressas com os dados obtidos foram inseridas nas respectivas planilhas eletrônicas do Microsoft Excel.

A entrevista realizada em cada unidade produtiva foi dirigida à obtenção do coeficiente de alteração do componente, para cada um dos indicadores de impacto, conforme avaliação do produtor em conjunto com o entrevistador. Os entrevistados responderam perguntas às diferentes questões relacionadas à produção, à preservação dos recursos naturais e às suas condições de vida na unidade de produção, antes e depois da adoção do manejo agroecológico da Caatinga, conforme o Ambitec - produção animal. Durante as entrevistas, foram feitos esclarecimentos relativos às variáveis analisadas. Com relação à contaminação biológica, foi elucidada sua definição, e os produtores avaliaram se houve melhoria desta variável em virtude do treinamento recebido e melhoria das condições de higiene.

Para avaliação das variáveis referentes à qualidade da água e do solo, assim como da presença de contaminantes, não foram utilizados kits para diagnósticos, portanto, os coeficientes de alteração para a qualidade da água não foram mensurados, e os dados referentes à qualidade do solo e de contaminantes tóxicos e biológicos foram obtidos exclusivamente pela percepção das modificações observadas pelos agricultores, durante o período de implantação da tecnologia.

Os coeficientes de alteração obtidos foram inseridos nas células das matrizes de avaliação de impacto ambiental, conforme o grau de alteração proporcionado pela tecnologia, e foram direcionados para atender à escala de ocorrência dessa alteração, que variou entre: pontual, quando o efeito se restringiu ao ambiente de implantação da tecnologia; local, quando o efeito se fez sentir fora do ambiente da tecnologia, mas restrito 
aos limites da unidade produtiva; e entorno, quando o impacto gerado ultrapassou os limites da unidade produtiva.

Os dados são automaticamente calculados com as planilhas, para determinação do impacto gerado pelos indicadores, e incluem os fatores de ponderação e a escala geográfica de ocorrência da alteração do componente. Os valores dos fatores de ponderação variam conforme o número de variáveis que formam um determinado indicador, e conforme sua importância para a formação do indicador. Essas ponderações juntas, somam uma unidade que poderá assumir valor positivo ou negativo, quando o componente contribui para um impacto ambiental positivo ou negativo. Se a variação do componente significa um impacto favorável, a soma dos fatores é positiva; se representar um impacto negativo, a soma dos fatores é negativa (Rodrigues et al., 2003). Nessa situação, deve-se enfatizar que os fatores nocivos, quando apresentam um coeficiente de alteração negativo, representam resultados positivos do componente.

Depois de inseridos os coeficientes de alteração, o coeficiente de impacto desse indicador é automaticamente calculado com uso do sistema, em função da escala de ocorrência e do fator ponderal. $\mathrm{O}$ coeficiente de impacto pode variar de +15 a -15 , a depender do direcionamento do impacto, se benéfico ou prejudicial, respectivamente.

O Ambitec também compõe um gráfico para cada indicador, bem como os agrega para compor o índice geral de impacto ambiental e seu respectivo gráfico. Ao final de todas as coletas, os dados de todos os produtores foram organizados em uma tabela, para que fosse possível a obtenção das médias dos componentes avaliados e a posterior análise descritiva (Tabela 1).

\section{Resultados e Discussão}

Os coeficientes de impacto gerados pelo mesmo indicador, em cada propriedade estudada (Tabela 1), e que compuseram a média do indicador, oscilaram bastante. Isso mostra que a implementação do manejo agroecológico da Caatinga gera efeitos que são influenciados pelas características de cada unidade produtiva, bem como pelo tipo de práticas conservacionistas adotadas.
O índice médio de impacto ambiental, gerado pelo manejo agroecológico da Caatinga nas sete unidades familiares estudadas, foi positivo (Tabela 1). Tupy et al. (2006) avaliaram o impacto ambiental das técnicas de produção intensiva, aplicadas às propriedades familiares produtoras de leite no Brasil, e Rodrigues et al. (2006) estudaram a integração tecnológica Embrapa Pecuária Sudeste, para produção leiteira na agricultura familiar, na região de Votuporanga, SP, obtiveram índices de impacto geral médio inferiores aos encontrados no presente estudo, que foram de 0,90 e 2,77, respectivamente. Pode-se observar que as maiores contribuições positivas, para a formação do índice de impacto geral, foram as de melhoria da capacidade produtiva do solo e da diminuição do uso de insumos materiais. A superioridade desses indicadores também foi observada por Rodrigues et al. (2006), que obtiveram coeficientes de impacto de 12,00 e 10,50 quanto à capacidade produtiva do solo e ao uso de insumos materiais, respectivamente.

Com relação à capacidade produtiva do solo, os coeficientes de alteração foram negativos, na maioria das propriedades, para as variáveis contaminantes tóxicos, erosão, perda de matéria orgânica, perda de nutrientes e compactação, o que produziu um coeficiente médio de impacto positivo. O que se pôde observar pelas entrevistas (Tabela 1) foi que a maior contribuição para a amplitude desse coeficiente foi a diminuição dos contaminantes tóxicos, a mitigação da erosão e, consequente, diminuição da perda de matéria orgânica e de nutrientes, além da redução dos fatores de compactação, com alta frequência de coeficientes de alteração benéficos. Nesse aspecto, as ações que podem ter contribuído, conforme apresentado na caracterização das unidades familiares, foram: a preservação das árvores, como preconizado nos métodos de manipulação da Caatinga, descritos por Cavalcante et al. (2007); a reciclagem de nutrientes, pelo aproveitamento dos restos vegetais; como, também, o plantio de essências nativas que estavam em vias de extinção em suas áreas produtivas, e plantio de exóticas adaptadas.

Galharte (2007), ao avaliar os impactos ambientais da integração lavoura-pecuária, observou que a maior cobertura do solo contribui para a redução da erosão, da perda de matéria orgânica e de nutrientes. A presença da vegetação nativa favorece a agregação de partículas do solo, o que colabora para a diminuição da erosão 
Tabela 1. Escala de ocorrência e fatores de ponderação, utilizados nas matrizes de ponderação da planilha Ambitec - produção animal, e os coeficientes de alteração e de impacto e índice geral de impacto ambiental do manejo agroecológico da caatinga, obtidos nas sete unidades familiares.

\begin{tabular}{|c|c|c|c|c|c|c|c|c|c|c|}
\hline \multirow[t]{2}{*}{ Indicador } & \multirow[t]{2}{*}{ Variável } & \multirow[t]{2}{*}{ E. $\mathrm{O}^{(1)}$} & \multirow[t]{2}{*}{ Fator $\mathrm{K}^{(2)}$} & \multicolumn{7}{|c|}{ Unidade familiar/coeficientes de alteração } \\
\hline & & & & 01 & 02 & 03 & 04 & 05 & 06 & 07 \\
\hline \multirow{6}{*}{$\begin{array}{l}\text { Uso de insumos } \\
\text { materiais }\end{array}$} & Insumos veterinários - frequência & 1 & 0,2 & -3 & -3 & -3 & -3 & -1 & -1 & -3 \\
\hline & Insumos veterinários - variedade & 1 & 0,2 & -3 & -3 & -3 & -3 & -1 & -1 & -1 \\
\hline & Insumos veterinários - resíduo & 1 & 0,3 & -3 & -3 & -3 & -3 & -1 & -1 & -3 \\
\hline & Alimentação - ração & 1 & 0,1 & -3 & -1 & -3 & -3 & -1 & 0 & -3 \\
\hline & Alimentação - volumosos/silagem & 1 & 0,1 & 0 & -1 & 3 & 3 & 0 & 0 & 1 \\
\hline & Alimentação - aditivos/suplementos & 1 & 0,1 & 0 & 0 & -1 & -1 & 0 & 0 & -1 \\
\hline \multicolumn{2}{|c|}{ Coeficiente de impacto } & & & 12,0 & 11,5 & 11,0 & 11,0 & 4,0 & 3,5 & 10,0 \\
\hline \multicolumn{4}{|c|}{ Coeficiente médio de impacto } & \multicolumn{7}{|c|}{9,00} \\
\hline \multirow{5}{*}{ Uso de energia } & Combustíveis fósseis - óleo e gás & 1 & 0,1 & 1 & 3 & 0 & 0 & 0 & 0 & 0 \\
\hline & Combustível fósseis - gasolina & 1 & 0,1 & 1 & 3 & 1 & 1 & 3 & 1 & 3 \\
\hline & Combustíveis fósseis - diesel & 1 & 0,1 & 1 & 0 & -1 & -1 & 0 & 0 & -3 \\
\hline & Biomassa - lenha & 1 & 0,075 & 3 & -1 & 0 & 0 & 0 & 0 & -3 \\
\hline & Eletricidade & 1 & 0,3 & 1 & 3 & 1 & 1 & 1 & 1 & 3 \\
\hline \multirow{2}{*}{\multicolumn{2}{|c|}{$\begin{array}{l}\text { Coeficiente de impacto } \\
\text { Coeficiente médio de impacto }\end{array}$}} & & & $-4,13$ & $-7,13$ & $-1,5$ & $-1,5$ & $-3,0$ & $-2,0$ & $-3,38$ \\
\hline & & & & & & & $-3,23$ & & & \\
\hline \multirow{4}{*}{$\begin{array}{l}\text { Uso de recursos } \\
\text { naturais }\end{array}$} & Água para dessedentação & 2 & 0,3 & 1 & 1 & 3 & 3 & 1 & 0 & 1 \\
\hline & Água para manejo & 2 & 0,3 & 0 & 0 & 0 & 0 & 0 & 0 & 1 \\
\hline & Área de pastagem & 2 & 0,2 & 1 & -1 & 0 & 0 & 0 & 0 & 1 \\
\hline & Área p/ disposição de resíduos & 2 & 0,2 & 0 & 0 & 1 & 1 & 0 & 0 & 3 \\
\hline \multirow{2}{*}{\multicolumn{2}{|c|}{$\begin{array}{l}\text { Coeficiente de impacto } \\
\text { Coeficiente médio de impacto }\end{array}$}} & & & $-1,0$ & $-0,2$ & $-2,2$ & $-2,2$ & $-0,6$ & 0,0 & $-2,8$ \\
\hline & & & & & & & $-1,29$ & & & \\
\hline \multirow{3}{*}{ Atmosfera } & Material particulado/fumaça & 5 & 0,4 & -3 & -3 & -3 & -3 & 0 & -3 & -3 \\
\hline & Odores & 5 & 0,1 & -3 & -3 & -3 & -3 & 0 & -3 & 1 \\
\hline & Ruídos & 5 & 0,1 & -3 & 0 & -1 & -1 & 0 & 0 & 1 \\
\hline \multirow{2}{*}{\multicolumn{2}{|c|}{$\begin{array}{l}\text { Coeficiente de impacto } \\
\text { Coeficiente médio de impacto }\end{array}$}} & & & 9,0 & 7,5 & 8,0 & 8,0 & 0,0 & 7,5 & 5,0 \\
\hline & & & & & & & 6,43 & & & \\
\hline \multirow{5}{*}{$\begin{array}{l}\text { Capacidade } \\
\text { produtiva do solo }\end{array}$} & Contaminantes tóxicos & 1 & 0,2 & -3 & -3 & -3 & -3 & 0 & -3 & -3 \\
\hline & Erosão & 1 & 0,2 & 0 & 0 & -3 & 0 & 0 & 0 & -3 \\
\hline & Perda de matéria orgânica & 1 & 0,2 & -3 & -3 & -3 & -3 & -3 & -3 & -3 \\
\hline & Perda de nutrientes & 1 & 0,2 & -3 & -3 & -3 & -3 & -3 & -3 & -3 \\
\hline & Compactação & 1 & 0,2 & -3 & -1 & -3 & -3 & 0 & -3 & -1 \\
\hline \multicolumn{2}{|c|}{ Coeficiente de impacto } & & & 12,0 & 10,0 & 15,0 & 12,0 & 6,0 & 12,0 & 13,0 \\
\hline \multicolumn{2}{|c|}{ Coeficiente médio de impacto } & & & & & & 11,43 & & & \\
\hline & Perda de vegetação nativa & 1 & 0,4 & 1 & 1 & -3 & 1 & 1 & 1 & -1 \\
\hline Biodiversidade & Perda de corredores de fauna & 1 & 0,3 & -3 & -3 & -3 & -3 & 1 & -1 & -3 \\
\hline & Perda de espécies/variedades caboclas & 1 & 0,3 & -3 & -3 & -3 & -3 & -1 & -3 & -1 \\
\hline Coeficiente de im & pacto & & & 1,4 & 1,4 & 3,0 & 1,4 & $-0,4$ & 0,8 & 1,6 \\
\hline Coeficiente médi & o de impacto & & & & & & 1,31 & & & \\
\hline & Solos degradados & 1 & 0,2 & -3 & -3 & -3 & -3 & 0 & -3 & -3 \\
\hline Recuperação & Ecossistemas degradados & 2 & 0,2 & -3 & -3 & -3 & -3 & -1 & -3 & -3 \\
\hline ambiental & Áreas de preservação permanente & 1 & 0,2 & 0 & 0 & 3 & 3 & 0 & 3 & 0 \\
\hline & Reserva legal & 1 & 0,4 & 0 & 0 & 0 & 0 & 0 & 0 & 0 \\
\hline Coeficiente de im & pacto & & & 1,8 & 1,8 & 2,4 & 2,4 & 0,4 & 2,4 & 1,8 \\
\hline Coeficiente médi & o de impacto & & & & & & 1,86 & & & \\
\hline Qualidade do & Resíduos químicos & 5 & 0,35 & -3 & -3 & -3 & -3 & -1 & -3 & -3 \\
\hline produto & Contaminantes biológicos & 5 & 0,35 & -3 & -3 & -3 & -3 & 0 & -3 & 0 \\
\hline Coeficiente de im & pacto & & & 10,5 & 10,5 & 10,5 & 10,5 & 1,75 & 10,5 & 5,25 \\
\hline Coeficiente médi & o de impacto & & & & & & 8,50 & & & \\
\hline Índice de impact & ambiental: & & & 4,68 & 4,00 & 5,19 & 4,68 & 0,91 & 3,92 & 3,40 \\
\hline Índice médio de i & mpacto ambiental: & & & & & & 3,83 & & & \\
\hline
\end{tabular}

${ }^{(1)}$ Escala de ocorrência (E.O.): 1, pontual; 2, local; 3, entorno. ${ }^{(2)}$ Fator K: fator de ponderação incluído automaticamente pela planilha Ambitec. 
melhora a estrutura do solo, e proporciona maior porosidade (Macedo, 2009).

No uso de insumos materiais, os coeficientes de alteração foram negativos quanto à frequência, variedade e resíduo do uso de insumos veterinários, o que indica redução do impacto ambiental. Houve redução no uso de ração e de aditivos e suplementos na alimentação e aumento no uso de volumoso e silagem (Tabela 1).

A adoção de preceitos ecológicos tem papel fundamental, pois a diminuição na frequência de uso e na variedade de insumos veterinários (Tabela 1) ocorre em virtude do uso das alternativas farmacológicas existentes na própria unidade de produção. Utilizam-se princípios fitoterápicos de espécies nativas da Caatinga, pelo emprego das práticas de armazenamento de forragem e maior disponibilidade de alimento, como afirma Araújo Filho et al. (2006).

Com relação a esse último fator, Veloso et al. (2004), ao trabalhar com diferentes dietas, concluíram que quanto maior o aporte de proteína na dieta de ovinos, maior a resistência dos animais a parasitas gastrintestinais, o que significa redução na administração de anti-helmínticos, por exemplo.

Atrelada à redução no uso e na variedade de insumos veterinários, vem a diminuição dos resíduos químicos (Tabela 1) presentes nos produtos e subprodutos produzidos pelos animais, que são disponibilizados à população. Esta diminuição está relacionada à redução no uso destes compostos no processo produtivo. Nascimento et al. (2001) estudaram a presença de resíduos de antibióticos no leite bovino tipo $\mathrm{C}$, tipo $\mathrm{B}$, tipo A e longa vida, em Piracicaba, SP, e observaram que $50 \%$ das amostras de leite analisadas continham resíduos. Na mensuração dessa variável, os produtores relacionaram a diminuição da utilização de produtos químicos à menor presença desses resíduos nos produtos.

Éimportante enfatizar que o indicador uso de insumos materiais só não foi mais expressivo porque a variável alimentação teve influência negativa (Tabela 1). Isso porque os agricultores afirmaram que houve maior fornecimento de alimentos aos animais, notadamente pelo maior uso de volumoso ou silagem (Tabela 1), em virtude do aumento dos rebanhos, da consciência da diminuição da pressão de pastejo das áreas de manejo, e da necessidade de depender o mínimo possível de insumos externos.
Quanto ao coeficiente obtido para o indicador qualidade do produto (Tabela 1), houve redução da presença de resíduos químicos e contaminantes biológicos, conforme percepção dos produtores.

A contaminação biológica é resultante da contaminação dos alimentos por microrganismos patogênicos que, segundo Pupin \& Tognon (2007), podem estar presentes na água não tratada corretamente e nos manipuladores que não têm higiene pessoal adequada. Sobre essas questões, em função do acompanhamento técnico e das capacitações, os agricultores perceberam que passaram a produzir alimentos com menos contaminantes biológicos, porque passaram a utilizar maior higiene na manipulação dos produtos, principalmente no abate de animais e na extração do mel de abelhas, o que fez com que produzissem alimentos mais seguros.

O indicador atmosfera (Tabela 1) teve grande participação na composição do índice geral de impacto graças à incorporação dos princípios agroecológicos no dia-a-dia dos agricultores familiares entre os quais estão: a diminuição da produção de material particulado, de fumaça e de odores, pela extinção da queima de madeira e pela diminuição da utilização de tratores e motosserras, entre outros equipamentos que também produziam fumaça e muito ruído.

Houve impacto positivo da tecnologia na biodiversidade e recuperação ambiental, e os coeficientes de alteração, em geral, indicaram redução das perdas de espécies, corredores de fauna, solos e ecossistemas degradados (Tabela 1). A diminuição das queimadas é altamente positiva no manejo agroecológico, pois, além de prejudicarem o meio ambiente pela emissão de poluentes, são responsáveis por toda uma mudança na composição florística e na estrutura da vegetação, e pelo comprometimento da reciclagem de nutrientes em consequência da queima da serrapilheira (Medeiros \& Miranda, 2005).

O uso de energia foi o indicador que contribuiu mais negativamente para o índice de impacto do manejo agroecológico da Caatinga. A contribuição negativa está associada a duas variáveis principais desse indicador: uso de gasolina e eletricidade (Tabela 1). O maior uso de gasolina pode estar associado à maior utilização dos transportes próprios para comercialização dos produtos e da necessidade de maior acompanhamento da área manejada. 
O outro indicador que contribuiu negativamente para o índice geral de impacto da tecnologia foi o uso de recursos naturais (Tabela 1). Em geral, os coeficientes de alteração indicam que houve aumento no uso de água para dessedentação e área para disposição de resíduos. A água servida aos animais, na maioria dos casos, era proveniente de poço tubular que, apesar de causar impacto no uso de recursos naturais, pelo menos ajuda na manutenção e na preservação dos mananciais, pois eles não têm acesso direto à fonte de água (açude, lagoa, rio).

$\mathrm{O}$ aumento da área de disposição de resíduo (Tabela 1) está relacionado ao amontoamento de esterco que antes se acumulava nos currais e, hoje, compõe as chamadas esterqueiras, cujo esterco depois de curtido é lançado nas áreas de produção e serve como fonte de reciclagem de nutrientes e de melhoria da estrutura física do solo.

\section{Conclusões}

1. O manejo agroecológico da Caatinga, nas unidades familiares, é benéfico ao meio ambiente, pois reduz o índice de impacto ambiental determinado pelo sistema Ambitec.

2. O manejo agroecológico da Caatinga aumenta a capacidade produtiva do solo, diminui o uso de insumos materiais e reduz a emissão de poluentes atmosféricos.

3. O uso de energia tem impacto ambiental negativo, em consequência do aumento dos custos com as variáveis eletricidade e gasolina, assim como o uso dos recursos naturais, em razão da maior necessidade de água para os animais e de área para armazenar os resíduos, o que onera os custos ambientais do manejo agroecológico da Caatinga.

\section{Referências}

ARAÚJO FILHO, J.A. de. Manipulação da vegetação lenhosa da Caatinga para fins pastoris. Sobral: Embrapa-CNPC, 1992. 18p. (Embrapa-CNPC. Circular técnica, 11).

ARAÚJO FILHO, J.A. de; CAVALCANTE, F.C.; SILVA, N.L. da. Criação de ovinos a pasto no semi-árido nordestino. Sobral: Embrapa Caprinos, 1999. (Embrapa Caprinos. Circular técnica, 19).

ARAÚJO FILHO, J.A. de; HOLANDA JÚNIOR, E.V.; SILVA, N.L. da; SOUSA, F.B. de; FRANÇA, F.M. Sistema agrossilvipastoril Embrapa Caprinos. In: LIMA, G.F. da C.; HOLANDA JÚNIOR, E.V.; MACIEL, F.C.; BARROS, N.N.; AMORIM, M.V.;
CONFESSOR JÚNIOR, A.A. (Org.). Criação familiar de caprinos e ovinos no Rio Grande do Norte: orientações para viabilização do negócio rural. Natal: Emater, 2006. p.193-210.

ÁVILA, A.F.D.; RODRIGUES, G.S.; VEDOVOTO, G.L. (Ed.). Avaliação dos impactos de tecnologias da Embrapa: metodologia de referência. Brasília: Embrapa Informação Tecnológica, 2008. 189 p.

BALANÇO social da pesquisa agropecuária brasileira. 2006. Brasília: Embrapa, 2006. 31p.

BALANÇO social da pesquisa agropecuária brasileira. 2009. Brasília: Embrapa, 2009. 25p.

BRASIL. Ministério da Agricultura, Pecuária e Abastecimento. Legislação para os sistemas orgânicos de produção animal e vegetal. Brasília: MAPA, 2009. 195p.

BRASIL. Ministério de Minas e Energia. Serviço Geológico do Brasil. Secretaria de Geologia, Mineração e Transformação Mineral. Projeto cadastro de fontes de abastecimento por água subterrânea: Rio Grande do Norte: diagnóstico do Município de Apodi. Recife: CPRM, 2005. 10p.

CAVALCANTE, A.C.R.; HOLANDA JÚNIOR, E.V.; SOARES, J.P.G. Produção orgânica de caprinos e ovinos. Sobral: Embrapa Caprinos, 2007. 40p. (Embrapa Caprinos. Documentos, 69).

CAVAlCANTE, A.C.R.; NEIVA, J.N.M.; CÂNDIDO, M.J.D.; VIEIRA, L. da S. Produção de ovinos e caprinos de corte em pastos cultivados sob manejo rotacionado. Sobral: Embrapa Caprinos, 2005. 17p. (Embrapa Caprinos. Circular técnica, 33).

COSTA, R.B. da; ARRUDA, E.J. de; OLIVEIRA, L.C.S. de. Sistemas agrossilvipastoris como alternativa sustentável para a agricultura familiar. Revista Internacional de Desenvolvimento Local, v.3, p.25-32, 2002.

DEPARTAMENTO INTERSINDICAL DE ESTATÍSTICA E ESTUDOS SOCIOECONÔMICOS. Estatística do meio rural. 3.ed. Brasília: DIEESE, 2008. 280p. Disponível em: $<$ http://www. dieese.org.br/anu/estatisticasMeioRural2008.pdf $>$. Acesso em: 1 dez. 2009.

GALHARTE, C.A. Avaliação de impactos ambientais da integração lavoura-pecuária: estudo de caso da inovação tecnológica da Embrapa. 2007. 107p. Dissertação (Mestrado) Universidade de São Paulo, Escola de Engenharia de São Carlos, São Carlos.

GOVERNO DO RIO GRANDE DO NORTE. Instituto de Desenvolvimento Sustentável e Meio Ambiente do RN. Perfil do seu município. Disponível em: <http://www.idema.rn.gov.br/ contentproducao/aplicacao/idema/socio_economicos/arquivos/ apodi/apodi.doc >. Acessado em: 10 mar. 2010.

HOLANDA JÚNIOR, E.V. Sistemas de produção de pequenos ruminantes no semi-árido do Nordeste brasileiro. Sobral: Embrapa Caprinos, 2006. 49p. (Embrapa Caprinos. Documentos, 66).

IRIAS, L.J.M.; RODRIGUES, G.S.; CAMPANHOLA, C.; KITAMURA, P.C.; RODRIGUES, I.; BUSCHINELLI, C.C. de A. Sistema de avaliação de impacto ambiental de inovações tecnológicas nos segmentos agropecuário, produção animal e agroindústria (Sistema AMBITEC). Jaguariúna: Embrapa Meio Ambiente, 2004. 8p (Embrapa Meio Ambiente. Circular técnica, 5). 
LIMA, M.H.B. Gestão ambiental em propriedades rurais: a questão do uso de defensivos agrícolas nas lavouras do Município de Jataí-Goiás. 2003. 133p. Dissertação (Mestrado) - Universidade Federal de Santa Catarina, Florianópolis.

MACEDO, M.C.M. Integração lavoura e pecuária: o estado da arte e inovações tecnológicas. Revista Brasileira de Zootecnia, v.38, p.133-146, 2009. Suplemento.

MEDEIROS, M.B. de; MIRANDA, H.S. Mortalidade pós-fogo em espécies lenhosas de campo sujo submetido a três queimadas prescritas anuais. Acta Botanica Brasilica, v.19, p.493-500, 2005.

MELO, M.; TONNEAU, J.P.; SOARES, D. Sistemas pecuários, convivência com a seca e manejo alimentar. In: SILVEIRA, L; PETERSEN, P.; SABOURIN, E. (Ed.). Agricultura familiar e agroecologia no semi-árido: avanços a partir do agreste da Paraíba. Rio de Janeiro: AS-PTA, 2002. p.219-233.

NASCIMENTO, G.G.F. do; MAESTRO, V.; CAMPOS, M.S.P. de. Ocorrência de resíduos de antibióticos no leite comercializado em Piracicaba, SP. Revista de Nutrição, v.14, p.119-124, 2001.

PUPIN, F.; TOGNON, J.H. Contaminação biológica: o risco invisível na era do alimento seguro. Hortifruti Brasil, ano 6, p.6-10, 2007.

RODRIGUES, G.S.; CAMPANHOLA, C. Sistema integrado de avaliação de impacto ambiental aplicado a atividades do Novo Rural. Pesquisa Agropecuária Brasileira, v.38, p.445-451, 2003.

RODRIGUES, G.S.; CAMPANHOLA, C.; KITAMURA, P.C. Avaliação de impacto ambiental da inovação tecnológica agropecuária: AMBITEC-AGRO. Jaguariúna: Embrapa Meio Ambiente, 2003. 95p. (Embrapa Meio Ambiente. Documentos, 34).

RODRIGUES, G.S.; RODRIGUES, I.A.; TUPY, O.; CAMARGO, A.C.; NOVO, A.L.M.; BONADIO, L.F.; TOKUDA, F.S.; ANDRADE, E.F.; SHIOTA, C.M.; SILVA, R.A. da. Avaliação sócio-ambiental da integração tecnológica Embrapa Pecuária Sudeste para produção leiteira na agricultura familiar. Revista Agricultura em São Paulo, v.53, p.35-48, 2006.

SAMPAIO, E.V.S.B.; ARAÚJO, M. do S.B.; SAMPAIO, Y.S.B. Impactos ambientais da agricultura no processo de desertificação no Nordeste do Brasil. Revista de Geografia, v.22, p.90-112, 2005.

TUPY, O.; PRIMAVESI, O. Avaliação dos impactos econômicos, sociais e ambientais de tecnologias da Embrapa Pecuária Sudeste. 3. Análise estratégica de custos de produção de leite. São Carlos: Embrapa Pecuária Sudeste, 2006. 23p. (Embrapa Pecuária Sudeste. Documentos, 56).

TUPY, O.; PRIMAVESI, O.; CAMARGO, A.C. de. Avaliação dos impactos econômicos, sociais e ambientais de tecnologias da Embrapa Pecuária Sudeste. 4. Técnicas de produção intensiva aplicadas a propriedades familiares produtoras de leite. São Carlos: Embrapa Pecuária Sudeste, 2006. 38p. (Embrapa Pecuária Sudeste. Documentos, 57).

VELOSO, C. de F.M.; LOUVANDINI, H.; KIMURA, E.A.; AZEVEDO, C.R.; ENOKI, D.R. de; FRANÇA, L.D. de; MCMANUS, C.M.; DELL'PORTO, A.; SANTANA, A.P. Efeitos da suplementação protéica no controle da verminose e nas características de carcaça de ovinos Santa Inês. Ciência Animal Brasileira, v.5, p.131-139, 2004.

Recebido em 16 de maio de 2010 e aprovado em 18 de setembro de 2010

Pesq. agropec. bras., Brasília, v.45, n.10, p.1073-1081, out. 2010 